\title{
Framework for the quantitative assessment of the risk of leakage from LNG-fueled vessels by an event tree-CFD
}

\author{
Shanshan FU ${ }^{\mathrm{a}, \mathrm{b}}$, Xinping YAN ${ }^{\mathrm{a}, \mathrm{b}}$, Di ZHANG ${ }^{\mathrm{a}, \mathrm{b}^{*}}$, Chaoyu LI ${ }^{\mathrm{c}}$, Enrico ZIO ${ }^{\mathrm{d}, \mathrm{e}}$ \\ a National Engineering Research Center for Water Transport Safety, China \\ b Intelligent Transport Systems Research Center, Wuhan University of Technology, China \\ c Liverpool Logistics, Offshore and Marine (LOOM) Research Institute, School of Engineering, Technology and Maritime Operations, \\ Liverpool John Moores University, UK \\ d Chaire Systems Science and the Energy Challenge, Fondation Electricite' de France (EDF), Laboratoire Genie Industriel, \\ CentraleSupélec, Université Paris-Saclay Grande voie des Vignes, 92290 Chatenay-Malabry, France \\ e Department of Energy, Politecnico di Milano, Italy
}

\begin{abstract}
:
Liquefied natural gas (LNG) is used as fuel in various kinds of vessels, e.g., passenger ship, ferry, cargo vessel and platform supply vessel (PSV). It is an eco-friendly bunker fuel with many advantages, like decreasing the emissions of $\mathrm{SO}_{\mathrm{X}}$ and particulate materials (PM) and meeting the international maritime organization (IMO) MARPOL Annex VI requirements on $\mathrm{NO}_{\mathrm{X}}$ emissions, and economic benefits compared to heavy fuel oil (HFO). However, the leakage of LNG-fuel is a threat for the safety of LNG-fueled vessels, due to its inflammable and explosive characteristics. This paper illustrates a framework for the quantitative risk assessment of LNG-fueled vessels with respect to potential leakage. For illustration purposes, reference is made to a typical LNG-fueled ship, as a representative case. Event tree analysis (ETA) and computational fluid dynamics (CFD) simulation are integrated for the investigation of the hazard, the analysis of the consequences, and the quantification the risk of the LNG leakage. The results of the study are used to provide risk control options (RCOs), in terms of optimal risk mitigation for LNG-fueled vessels.
\end{abstract}

Keywords: Liquefied natural gas-fueled vessel; Event tree analysis; Computational fluid dynamics simulation; Leakage analysis; Quantitative risk assessment

\section{Introduction}

LNG is a valuable and eco-friendly bunker fuel produced by compressing and cooling natural gas down to approximately -162 degrees Celsius, after desulfurizing and removing particulate matters (Kumar et al., 2011; Woodward \& Pitbaldo, 2010). The use of this pure chemical product (with few sulphur elements and zero PM) as power source in the marine engine allows LNG-fueled vessels not only to meet the requirements of the international convention for the prevention of pollution from ships (MARPOL Annex VI) for both worldwide trade and operations in the emission control areas (ECAs), without the need for the extra exhaust gas treatment, but also to fit the regulations of international code of safety for ships using gases or other low-flashpoint fuels (IGF code). Due to the huge reserves of natural gas and the policies on exhaust emission reduction of $\mathrm{NO}_{\mathrm{X}}, \mathrm{SO}_{\mathrm{X}}$ and $\mathrm{PM}$, LNG is considered as a prior alternative marine fuel for the future (Gohary et al., 2012).

Substantial effort has been made on design, survey/experiment, standardization, safety research for LNG-fueled vessels. Wartsila designed marine LNG-diesel dual fuel engines with less release of $\mathrm{NO}_{\mathrm{X}}, \mathrm{SO}_{\mathrm{X}}$ and PM than the same power diesel engines (Brett, 2008). In 2009, IMO authorized an interim guideline MSC 285(86) (IMO, 2009), which officially accepted natural gas as a legitimate power source for various types of ships. Det Norske Veritas (DNV) surveyed several dozen newly built LNG-fueled ships before the end of 2009 (Bagniewski, 2010). In 2014, IMO approved the international code for ships using gases or other low-flashpoint fuels (IGF code, 2014). The IGF code became mandatory and was adopted in June 2015, and will be come into force in 2017. In addition, American Bureau of Shipping (ABS) adopted a guide "Propulsion and auxiliary systems for gas fueled ships" (ABS, 2011), and DNV and Germanischer Lloyd (GL) published a research report on the safety assessment of generic LNG-fueled vessels (DNV and GL, 2012). Also, Chinese shipping enterprises have transformed twelve diesel-fueled vessels into LNGfueled vessels before June 302013 (Fu et al., 2014).

Despite the benefits of LNG implementation (Kumar et al., 2011), the inherent hazardous characteristics of LNG cannot be neglected, such as inflammability, explosiveness and ultralow temperature. For instance, if LNG went to spill from the storage equipment, the liquid would vapor and diffuse very fast, and the risks of fire and explosion would increase with the spread of natural gas. Hence, the importance of safety for LNG technologies attracts global attention. At present, not only academia but also practitioners have adopted approaches to investigate the risks of LNG terminals or LNG carriers. Specifically, Raj and Lemoff (2009) discussed and compared the differences between risk associated standards NFPA 59A standard (2009 edition) and EN 1473 (2006) for LNG facility siting, Mannan et al. (2009) proposed a risk assessment methodology for LNG important terminals by incorporating 
Bayesian and LOPA approaches, and using relevant offshore reliability data (OREDA) (SINTEF Industrial Management, 2002), Paltrinieri et al. (2015) used a dynamic procedure for atypical scenarios identification (DyPASI) to identify atypical accident scenarios in LNG terminals, and Lee et al. (2015) compared the fire risk assessments of the two types of LNG fuel gas supply (FGS) systems. Taking into consideration the evaporation losses of water spill areas, Fay $(2003,2007)$ provided an analysis of the spread of a large LNG spill, the duration time of pool fire, and the pattern of heat release, and Davies et al. (2013) summarized the release likelihood data used and provided an example of its use for a simplified LNG fueling system. As for LNG carriers, Vanem et al. (2008) presented a generic risk assessment of the global operations of ocean-going LNG carriers on the basis of Event Tree Analysis (ETA), Chang et al. (2008) investigated the availability and safety concerns of the conventional and prospective propulsion systems for LNG carriers, Elsayed (2009) developed a multiple attributes risk assessment approach to investigate the LNG carrier's loading and offloading risks at the terminal sites, Pitblado and Woodward (2011) highlighted some experiment and modeling approaches for risk analysis of LNG carriers, Nwaoha et al. (2013) constructed a mathematical model of the LNG carrier control system and carried out a corresponding risk assessment combined with genetic algorithms.

From an in-depth analysis, the majority of the proposed research appears to focus on studying the risk of large scale LNG infrastructures, such as LNG terminals and carriers. For LNG as the power onboard, it appears that limited work has been performed on quantitative risk assessment, except for LNG carriers. To fill the gap, this paper proposes a framework for quantitative risk assessment of LNG-fueled vessels with respect to potential leakage, including hazard identification and frequency analysis, accident scenario analysis and consequence simulation. ETA and CFD simulation are integrated for the probability estimation of accident scenarios and three-dimensional consequences simulation of the LNG-fueled vessels leakage events, respectively. The primary feature of the framework is that it enables to measure the probability of accident scenarios for various initiating events, which are the likelihoods of fire and explosion accidents for LNG-fueled vessels leakage events in this paper. The severity of consequence for the accident scenarios can be also analyzed and evaluated by CFD simulation. The dimension and arrangement of the vessel used in the CFD simulation are from a typical LNG-fueled ship. The results are compared and validated with several relevant studies from DNV and GL (2012), and the results of the validation show strong agreement. The framework provides an insight into the combined of effect of hazardous events on the probability and consequence of fire and explosion accidents for LNG-fueled vessels. In principle, it can assist in providing risk control options (RCOs) in terms of optimal risk mitigation for LNG-fueled vessels.

The remaining sections of the paper are structured as follows. In section 2, a systematic framework of risk assessment of LNG-fueled vessels, including the hazard identification, probabilistic modeling and consequences simulation, is developed. In section 3, a typical LNG-fueled vessel is chosen as a reference system to conduct the quantitative assessment of LNG leakage events. Its feasibility is validated by comparison with several relevant studies in section 4. Finally, section 5 consists of conclusions and remarks on the work and its results.

\section{Methodology and framework}

\subsection{Risk concept}

Risk is a function of the initiating event, the state of the system and of its environment, and the time frame (Haimes, 2009). A traditional perspective for risk metric/description is presented as follows (Aven, 2012): Risk=Probability and scenarios/ (severity of) consequences $(\mathrm{R}=\mathrm{P} \& \mathrm{C})$. Namely, risk is a measure of the probability and severity of adverse effects (Lowrance, 1976), the combination of probability and extent of consequences (Ale, 2002) or magnitude/ severity of consequences (SRA, 2015).

The above metrics/definitions of the concept of risk indicate that risk should be analyzed in both aspects of likelihood/probability of accident occurrence and associated consequences. In this paper, we take the following description of risk with reference to a generic $i$-th initialing event, which combines probabilities and consequences (Ren et al., 2005):

$$
\left.\operatorname{Risk}_{i}=p_{i} *\left[\sum_{j=1}^{N} \mathrm{C}_{i, j} * q_{i, j}\right)\right]
$$

where $i$ is the index of the element of the set $\mathrm{A}$ of initiating events, whose generic element $\mathrm{A}_{i}$ is a specific initiating event, $p_{i}$ is the likelihood of occurrence of the initiating event $\mathrm{A}_{i}, j$ is the index of the possible consequences deriving from scenario $\mathrm{A}_{i}, \mathrm{C}_{i, j}$ is the magnitude of the possible consequences caused by event $\mathrm{A}_{i}$ and $q_{i, j}$ is the conditional probability that these consequences develop, given that the accident $\mathrm{A}_{i}$ occurred.

Consequence categories are described in Table 1: the definitions conform to the consequence scale for hazard identification (HAZID) of generic LNG-fueled vessels (DNV and GL, 2012). 
Table 1

Consequence scale used in the risk assessment.

\begin{tabular}{cl}
\hline Severity & \multicolumn{1}{c}{ Definition } \\
\hline Moderate (1) & On site: no permanent effects \\
& External: no effect \\
Serious (2) & On site: permanent effects \\
& External: non- permanent effects \\
Major (3) & On site: one fatality and/or several permanent invalidities \\
& External: permanent effects \\
Catastrophic (4) & On site: several fatalities \\
& External: one fatality; many physical injuries \\
& On site: many fatalities \\
Disastrous (5) & External: several fatalities \\
\hline
\end{tabular}

\subsection{Event tree analysis}

ETA is an inductive logic, graphically supported approach for identifying the various accident sequences that may result from a given initiating event (Reason, 1997; Zio, 2007; Zio et al., 2009). The probability of each accident sequence can be estimated by multiplication of the conditional probabilities of each node along the sequence from the initiating event to the end.

\subsection{Computational fluid dynamic simulation}

CFD is a branch of fluid mechanics that uses numerical methods and algorithms to solve nonlinear problems that involve fluid flows. It is widely used in practice, e.g. in combustion numerical simulation (Hua et al., 2005). It is suggested also as an appropriate approach to simulate vapor dispersion and blast. With the development of computer technology, high speed computers are available to perform calculations in three dimensions (Harlow, 2004).

FLACS (Hanna et al., 2004) is a leading CFD tool used for the prediction of the consequence of LNG release. Hansen et al. (2010, 2014), validated the simulation results of FLACS against an experimental data set for LNG vapor dispersion, and demonstrated that FLACS can be considered a suitable model to accurately simulate the dispersion of vapor from an LNG release (Cormier et al., 2009).

\subsection{Framework of quantitative risk assessment}

A framework of quantitative risk assessment to estimate the potential risk of LNG-fueled vessels leakage is proposed in terms of the above illustrated perspectives of risk and related quantitative techniques. Specifically, the framework consists of the following seven steps, as shown in Fig. 1.

(1) Definition of the scope of study and data collection. Introduce research background, clarify the components or subsystems of the system under analysis and describe the limitations and boundaries of the work. Collect appropriate data from historical records, expert judgments or the combination of the above aspects.

(2) Hazard identification. Based on the collected data, identify the initiating events A $i$ of LNG-fueled vessels leakage during voyage, find the causes of each event, and then estimate the likelihood of occurrence of initialing events.

(3) Consequence scenarios analysis. Analyze the possible outcomes of the accident sequence resulting from the initialing events, by studying the dynamic propagation process. Calculate the associated consequence probabilities on the basis of the ETA method.

(4) Consequence simulation. Model a LNG-fueled vessel by three-dimensional CFD simulation and estimate the severity of consequences according to the simulation results.

(5) Risk assessment. Aggregate the likelihood of initiating event occurrence, the accident sequence consequence probability and severity of consequence as Eq. (1).

(6) Validation. Discuss and verify the analysis findings by comparing with relevant existing results.

(7) Recommendations. Propose risk control options (RCOs) to provide guidance for improving the risk management of LNG-fueled vessels, based on the risk assessment results. 


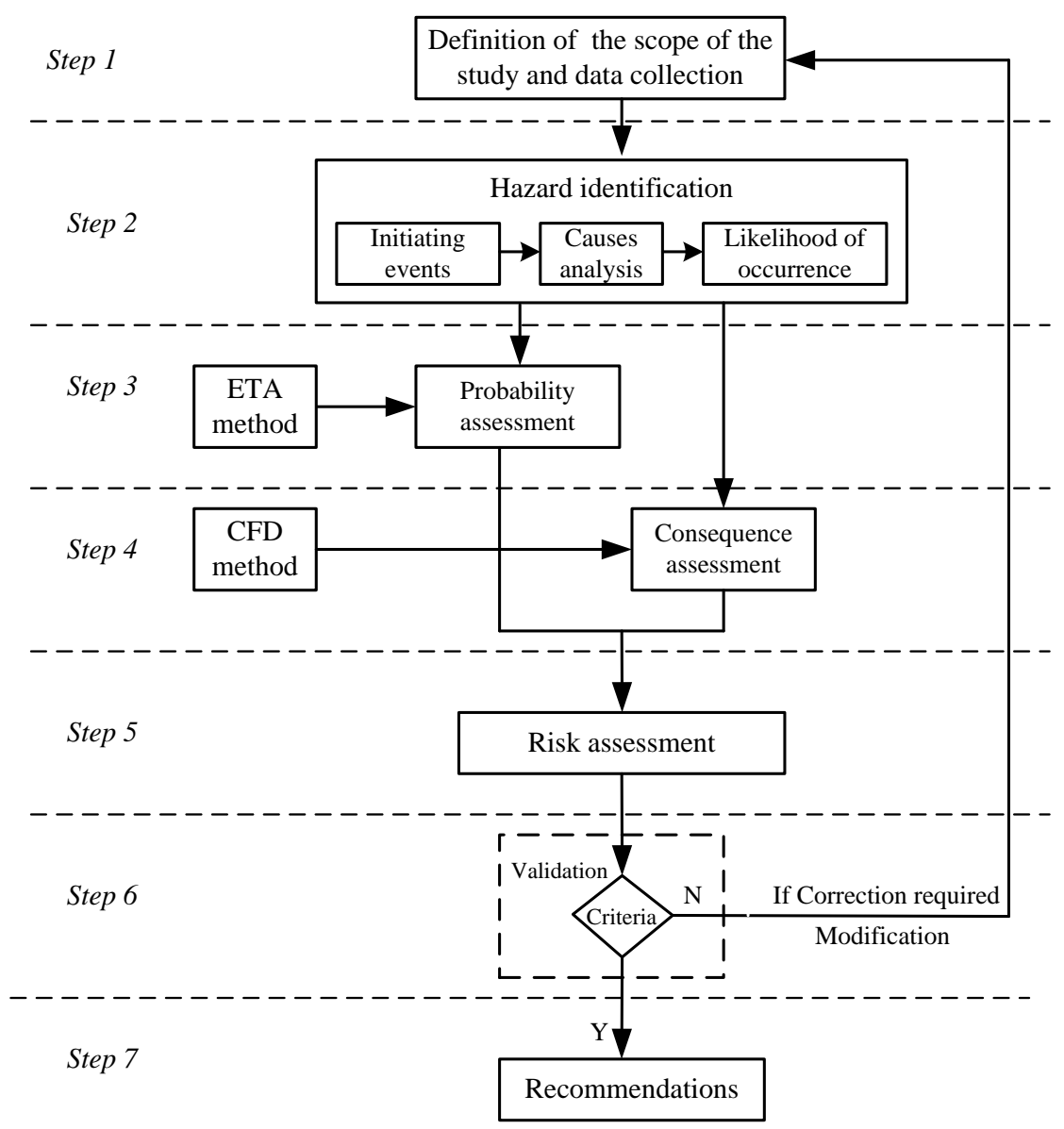

Fig. 1. Framework for risk assessment proposed.

Specifically, the above framework is used for quantitative risk assessment of fire and explosion accidents in oil $\&$ gas installations, e.g. LNG-fueled vessels, LNG terminals, oil tank trucks. The framework enables to measure the probability of accident scenarios for various initiating events by ETA, which is the likelihoods of fire and explosion accidents for LNG-fueled vessels leakage events in this paper. The severity of consequence for the accident scenarios can be also analyzed and evaluated by CFD simulation with regard to the actual size and arrangement of LNG-fueled vessel. By compared with alternative risk assessment framework, e.g. NORSOK standard z-013 (Norwegian Technology Centre, 2001), this framework is able to quantify the probability of accident scenarios from the initiating events to the outcome accidents, simulate and evaluate the severity of consequences for these accident scenarios, integrate the results from probability analysis, severity of consequence analysis, and comprehensive assess the risks of potential events like LNG-fueled vessels leakage events.

\section{Case study}

This section describes the quantitative risk assessment process based on the framework that was proposed in Section 2.4. A typical LNG-fueled ship Hongri 166 is chosen as a target vessel to interpret and demonstrate each step of the proposed quantitative risk assessment framework. Specially, the model used in the CFD simulation is developed with regard to the size and arrangement of Hongri 166.

\subsection{Definition of the scope of study and data collection}

This study focuses on the risk analysis of LNG-fueled vessel leakage, during the shipping voyage, neglecting loading and unloading processes. The consideration is for the risks to crew and third party onboard, whereas property loss or environmental damage caused by LNG leakage is out of consideration.

The ship data of Hongri 166 is reported shown in Table 2. It belongs to a regular shipping line in the Yangtze River (between Shanghai and Huangshi ports) (Changjiang River Administration of Navigational Affairs, 2012). The layout arrangement of this LNG-fueled cargo ship is illustrated in Fig. 2. 
Table 2

The ship data of Hongri 166

\begin{tabular}{cc}
\hline type & General cargo \\
\hline Dead Weight tonnage (DWT) & $2.64 \mathrm{E}+03 \mathrm{ton}$ \\
Length & $75.3 \mathrm{~m}$ \\
Breadth (width) & $13.0 \mathrm{~m}$ \\
Depth & $5.45 \mathrm{~m}$ \\
LNG container & $15.0 \mathrm{~m}^{3}($ on deck) \\
\hline
\end{tabular}

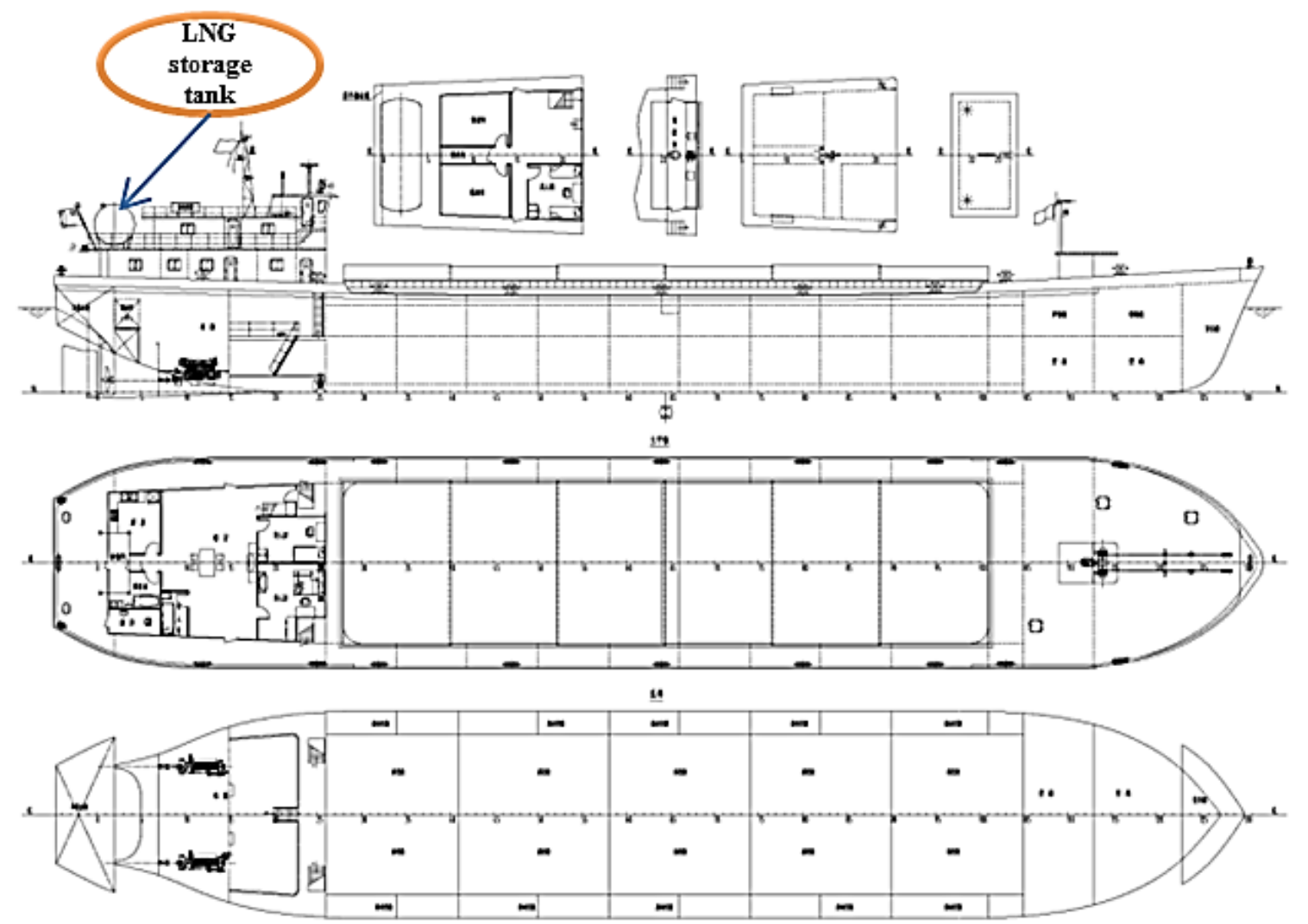

Fig. 2. Layout arrangement of Hongri 166.

\subsection{Hazard identification}

\subsubsection{Initiating events}

For a LNG-fueled power system, there are numerous pipes (e.g., DN10 and DN40), flange connectives and valves. According to the relevant research in LNG ships and terminals (Raj and Lemoff, 2009; Woodward and Pitbaldo, 2010; DNV and GL, 2012), the possible leakage of LNG occurs in these places, as well as in the storage tank itself. In this study, LNG leakage modes from diverse LNG storage and sealing equipment are assumed as the initialing events, as listed in Table 3 with reference to the real diameters of the storage tank, pipes, flange connections or valves onboard.

Table 3

Initiating events of LNG-fueled vessels leakage.

\begin{tabular}{cccc}
\hline Event $A_{i}$ & Components & Leakage modes & Typical release diameter $(\mathrm{mm})$ \\
\hline$A_{1}$ & Storage tank $15.0 \mathrm{~m}^{3}$ & Small leakage & 5.00 \\
$A_{2}$ & Storage tank $15.0 \mathrm{~m}^{3}$ & Medium leakage & 50.0 \\
$A_{3}$ & Storage tank $15.0 \mathrm{~m}^{3}$ & Large leakage & 100 \\
$A_{4}$ & Pipe DN40 & Small leakage & 50.0 \\
$A_{5}$ & Pipe DN40 & Medium leakage & 25.0 \\
$A_{6}$ & Pipe DN10 & Small leakage & 5.00 \\
$A_{7}$ & Pipe DN10 & Large leakage & Rupture $(10.0)$ \\
$A_{8}$ & Flange connection or valve DN40 & Small leakage & 5.00 \\
$A_{9}$ & Flange connection or valve DN40 & Medium leakage & 25.0 \\
$A_{10}$ & Flange connection or valve DN10 & Small leakage & 5.0 \\
$A_{11}$ & Flange connection or valve DN10 & Large leakage & Rupture $(10.0)$ \\
\hline
\end{tabular}




\subsubsection{Analysis of causes and likelihood of occurrence}

The probable failure causes of the storage tank, pipes, flanges connections or valves have been systematically identified through real ship investigation and extent workgroup discussion. The possible causes for LNG leakage onboard are:

1. breach/ malfunction of tank or pipe structures;

2. crack due to fatigue;

3. dropped objects penetrating LNG tank;

4. failure of equipment or piping;

5. fire caused by other events onboard or on other vessels, escalating to the LNG tank or gas piping system;

6. high energy collision penetrating LNG tank or pipes;

7. human error;

8. lack of tank protection;

9. large filling volume of LNG and pressure;

10. no standard flange connections for LNG bunkering;

11. production error;

12. same causes as small leakage resulting in larger spill due to larger hole size;

13. wear and tear.

Notice that a certain cause may lead to several concurrent events and a given event may occur due to various causes. Based on the causes listed above, the corresponding causes of each event are identified and analyzed. LNGfueled vessel is a new type of vessels in China and, thus, there is little historical data. LNG terminals of the same size of the ship's LNG associated equipment from China Academy of Safety Science and Technology (CASST, 2012) are adopted in this case study. The corresponding likelihood of occurrence of each event and probable failure causes are listed in Table 4.

\section{Table 4}

Causes of initiating events $A_{i}$ and associated likelihood.

\begin{tabular}{ccc}
\hline Event $A_{i}$ & Causes & Likelihood of occurrence (release per year) \\
\hline$A_{1}$ & $1,3,5,8,11$ & $1.00 \mathrm{E}-07$ \\
$A_{2}$ & $1,3,5,6,8,11$ & $5.00 \mathrm{E}-06$ \\
$A_{3}$ & $1,3,5,6,8$ & $5.00 \mathrm{E}-07$ \\
$A_{4}$ & $4,5,9,11$ & $3.00 \mathrm{E}-06$ \\
$A_{5}$ & $4,5,6,9,11,12$ & $6.00 \mathrm{E}-07$ \\
$A_{6}$ & $4,5,9,11$ & $1.00 \mathrm{E}-05$ \\
$A_{7}$ & $4,5,6,9,11,12$ & $3.00 \mathrm{E}-07$ \\
$A_{8}$ & $2,7,9,10,11,13$ & $2.78 \mathrm{E}-06$ \\
$A_{9}$ & $2,7,9,10,11,12,13$ & $3.45 \mathrm{E}-07$ \\
$A_{10}$ & $2,7,9,10,11,13$ & $2.78 \mathrm{E}-06$ \\
$A_{11}$ & $2,7,9,10,11,12,13$ & $1.50 \mathrm{E}-07$ \\
\hline
\end{tabular}

According to the data listed in Table 4, the occurrence likelihood of the large leakage diameters in general is slightly smaller than that of the small leakage diameters to pipes, flange connections or valves. Both small and large leakages diameters of the storage tanks (event $A_{1}$ and event $A_{3}$ ) have smaller likelihood of occurrence compared with medium leakage diameters of the storage tank (event $A_{2}$ ).

\subsection{Consequence scenario analysis}

Consequence scenario analysis is conducted based on ETA and a LNG leakage model adapted from a liquid spill model (Vílchez et al., 2011), as illustrated in Fig. 3. In the LNG leakage model, there are three possibilities: immediate ignition, delayed and flame front acceleration. The final scenarios of LNG leakage are: flash fire, vapor cloud explosion (VCE) and pool fire or jet fire.

The event tree shown in Fig. 3. describes the diverse possibilities:

1. $\quad p_{a}$ refers to the probability of immediate ignition, which is established based on the release flow rate $m$ (Ronza et al., 2007). If $m$ is less than $10.0 \mathrm{~kg} / \mathrm{s}$, the corresponding probability is 0.200 ; if $m$ is between 10.0 $\mathrm{kg} / \mathrm{s}$ and $100 \mathrm{~kg} / \mathrm{s}$, the associated probability is set to 0.500 ; and if $m$ is large than $100 \mathrm{~kg} / \mathrm{s}$, the probability under this condition is 0.700 .

2. $\quad p_{b}$ refers to the probability of delayed ignition: if the lower flammability limit (LFL) of LNG exceeds established boundary, the corresponding probability of delayed ignition is defined as 1.00 (BEVI Reference 
Manual, 2009) because the possibility of intervention in the event of a flammable cloud is minimal; if LNG leakage is characterized as process release, the highest value of delayed ignition given by BEVI is 0.700 ; if it is difficult to find out the direct link between LNG leakage in the working process and ignition source, the corresponding probability of delayed ignition is set to 0.100 (Ronza et al., 2007); if LNG leakage is considered as storage releases, the associated probability is defined as 0.07 (CPR 18E, 1999).

3. $p_{c}$ refers to the probability of flammable front acceleration, which is set to 0.400 (Vílchez et al., 2011).

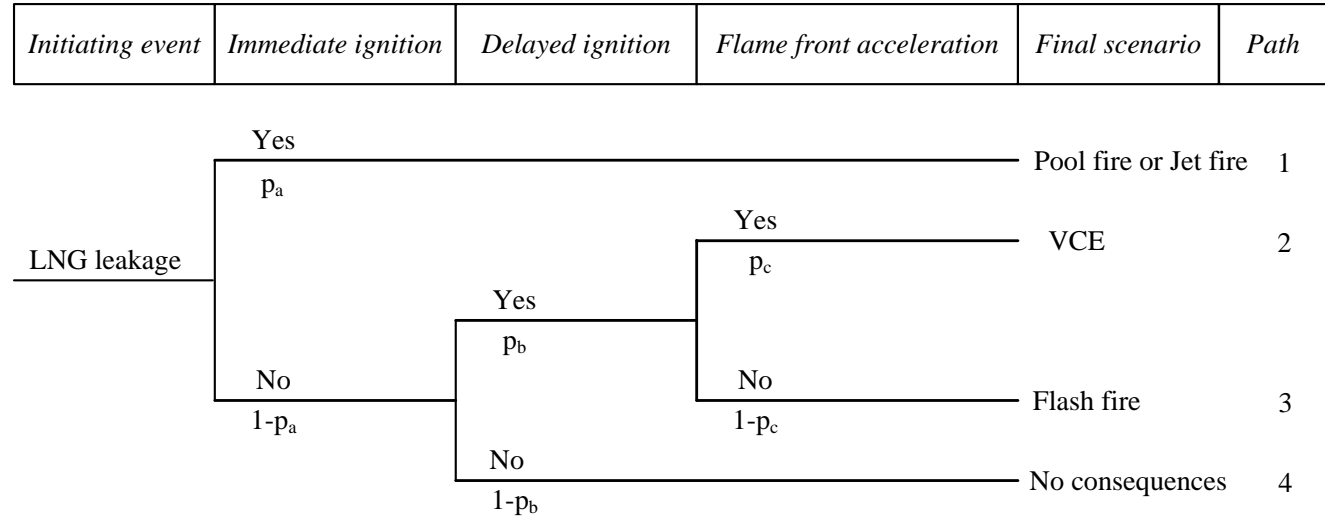

Fig. 3. LNG leakage ETA model.

The probability of each scenario is calculated by multiplying the likelihood of the initialing event and the conditional probabilities along the scenarios of immediate ignition $\left(p_{a}\right)$, delayed ignition $\left(p_{b}\right)$, and flame front acceleration $\left(p_{c}\right)$ :

$$
\begin{aligned}
& p(\text { path } 1)=p_{a}, \\
& p(\text { path } 2)=\overline{p_{a}} * p_{b} * p_{c}, \\
& p(\text { path } 3)=\overline{p_{a}} * p_{b} * \overline{p_{c}}, \\
& p(\text { path } 4)=\overline{p_{a}} * \overline{p_{b}},
\end{aligned}
$$

where $\overline{p_{a}}=1-p_{a}, \overline{p_{b}}=1-p_{b}$ and $\overline{p_{c}}=1-p_{c}$.

For the addressed probability of immediate ignition $p_{a}$, the influencing factor is the release flow rate, which can be computed as:

$$
m_{i}=\frac{\pi * d_{i}^{2}}{4} * \rho, i=1,2 \ldots, 11 .
$$

where $i$ is the index of the initiating events, $m_{i}$ is the release flow rate $(\mathrm{kg} / \mathrm{s})$ in event $A_{i}, d_{i}$ is the diameter of the corresponding release aperture $(\mathrm{m})$, and $\rho$ is the density $\left(\mathrm{kg} / \mathrm{m}^{3}\right)$ of LNG that approximately equals to $426 \mathrm{~kg} / \mathrm{m}^{3}$ (Woodward \& Pitbaldo, 2010). The value of each flow rate $m_{i}$ for event $A_{i}$ is listed in Table 5. The values of release flow rate $m_{i}$ for all the events are less than $10 \mathrm{~kg} / \mathrm{s}$; therefore, the corresponding probabilities of immediate ignition are 0.200 according to Ronza et al. (2007).

Table 5

Release flow for event $A_{i}$.

\begin{tabular}{ccc}
\hline Event $A_{i}$ & Release diameter $(\mathrm{mm})$ & Release flow rate $m_{i}(\mathrm{~kg} / \mathrm{s})$ \\
\hline$A_{1}$ & 5.00 & $8.36 \mathrm{E}-03$ \\
$A_{2}$ & 50.0 & $8.36 \mathrm{E}-01$ \\
$A_{3}$ & 100 & 3.35 \\
$A_{4}$ & 50.0 & $8.36 \mathrm{E}-01$ \\
$A_{5}$ & 25.0 & $2.09 \mathrm{E}-01$ \\
$A_{6}$ & 5.00 & $8.36 \mathrm{E}-03$ \\
$A_{7}$ & 10.0 & $3.35 \mathrm{E}-02$ \\
$A_{8}$ & 5.00 & $8.36 \mathrm{E}-03$ \\
$A_{9}$ & 25.0 & $2.09 \mathrm{E}-01$ \\
$A_{10}$ & 5.0 & $8.36 \mathrm{E}-03$ \\
$A_{11}$ & 10.0 & $3.35 \mathrm{E}-02$ \\
\hline
\end{tabular}


The parameter $p_{b}$ describes the conditional probability of delayed ignition. In pipe, flange connection or valve leakage scenarios, it is usually taken $p_{b}=1.00$ (Vílchez et al., 2011), because the possibility of intervention in the event of a flammable cloud is minimal; for the remaining events of leakage in the working process, $p_{b}=0.700$. Flame front acceleration is used to describe the generated intense shear flow. The conditional probability of flame front acceleration is set to 0.400 in this study. Applying Eqs. (3) and (4), the resulting probabilities of the different consequences are reported in Table 6.

Table 6

Consequences occurrence probability for flash fire and VCE scenarios.

\begin{tabular}{cccccc}
\hline \multirow{2}{*}{ Event $A_{i}$} & \multicolumn{3}{c}{ Most likely scenario } & \multicolumn{2}{c}{ Consequences probability } \\
\cline { 2 - 6 } & $p_{a}$ & $p_{b}$ & $p_{c}$ & Flash fire (path 3) & VCE (path 2) \\
\hline$A_{1}$ & 0.200 & 1.00 & 0.400 & 0.336 & N/A \\
$A_{2}$ & 0.200 & 0.700 & 0.400 & 0.336 & 0.224 \\
$A_{3}$ & 0.200 & 0.700 & 0.400 & 0.336 & 0.224 \\
$A_{4}$ & 0.200 & 1.00 & 0.400 & 0.480 & N/A \\
$A_{5}$ & 0.200 & 1.00 & 0.400 & 0.480 & N/A \\
$A_{6}$ & 0.200 & 1.00 & 0.400 & 0.480 & N/A \\
$A_{7}$ & 0.200 & 1.00 & 0.400 & 0.480 & N/A \\
$A_{8}$ & 0.200 & 1.00 & 0.400 & 0.480 & N/A \\
$A_{9}$ & 0.200 & 1.00 & 0.400 & 0.480 & N/A \\
$A_{10}$ & 0.200 & 1.00 & 0.400 & 0.480 & N/A \\
$A_{11}$ & 0.200 & 1.00 & 0.400 & 0.480 & N/A \\
\hline
\end{tabular}

The probability of flash fire accident of event $A_{i}(i=1,2,3)$ and $A_{i}(i=4, \ldots, 11)$ is as 0.336 and 0.48 , respectively. The probability of VCE accident of event $A_{2}$ and event $A_{3}$ is 0.224 . It is indicated that the pool fire and jet fire accidents rarely occur under small flow rates (no more than $3.35 \mathrm{~kg} / \mathrm{s}$ ) (API, A., 2000). Thus, the pool fire and jet fire accidents fall out of the scale of the present work. On the contrary, the explosions are only taken into consideration in event $A_{2}$ and event $A_{3}$, because it is unlikely that they occur in small release aperture scenarios under the strict forming conditions (Gavelli et al., 2011).

\subsection{Consequence simulation}

It is difficult to obtain relevant historical data of accident to support empirical estimation of consequences, given the limited operational experience of LNG-fueled vessels. To circumvent this obstacle in the analysis, the FLACS CFD simulation method is used for consequence modeling in LNG leakage analysis.

Firstly, a three-dimensional simulation model is developed according to the real hull structure and configuration of Hongri 166, as shown in Fig. 4. Then, the simulation conditions are defined, assuming that there is no other ship in the surrounding. The LNG component, explosive limits, and environmental conditions are, then, considered for estimating the risk consequence:

1. LNG component is 'second line of natural gas from west to east' in China, constituted by $\mathrm{CH}_{4}(92.5 \%)$, $\mathrm{C}_{2} \mathrm{H}_{6}(3.96 \%), \mathrm{C}_{3} \mathrm{H}_{8}(0.335 \%), \mathrm{i}-\mathrm{C}_{4} \mathrm{H}_{10}(0.116 \%), \mathrm{n}^{-} \mathrm{C}_{4} \mathrm{H}_{10}(0.0863 \%), \mathrm{i}-\mathrm{C}_{5} \mathrm{H}_{12}(0.221 \%), \mathrm{CO}_{2}(1.89 \%)$ and $\mathrm{N}_{2}(0.846 \%)$

2. upper flammability limit (UFL) for LNG is $1.50 \mathrm{E}+05 \mathrm{ppm}$, and the LFL is $5.00 \mathrm{E}+04 \mathrm{ppm}$ (Wang and Zheng, 2010);

3. wind speed is $3.00 \mathrm{~m} / \mathrm{s}$;

4. ambient temperature is 20.0 degrees Celsius.

These assumptions have been validated by five experts in the field from CASST, Wuhan University of technology and China International Marine Containers (CIME) - ENRIC.

Given the pre-defined conditions mentioned above, the consequences severity categories are derived from the FLACS CFD simulation (Arnold et al., 2002) results. The results under flash fire and VCE scenarios are illustrated in the following.

\subsubsection{Flash fire}

To evaluate the consequences magnitude, coverage is used in flash fire accidents, which is defined as the dangerous zone with 50\% likelihood of human death (Gavelli et al., 2011). The simulation results of events $A_{1}, A_{2}$ and $A_{3}$ under flash fire are shown in Fig. 5. Since the ranges of dangerous zones change with wind direction, a maximum radius is used for the description of the consequences of flash fire. In Fig. 5, the maximum radiuses of these three scenarios are $3.24 \mathrm{~m}, 20.5 \mathrm{~m}$ and $56.2 \mathrm{~m}$, respectively. As expected, a large leakage aperture results in 
wide coverage, i.e. severe consequences. Similar simulation results have been obtained for the remaining events $A_{i}\{4, \ldots, 11\}$, which are not presented here due to limited space.

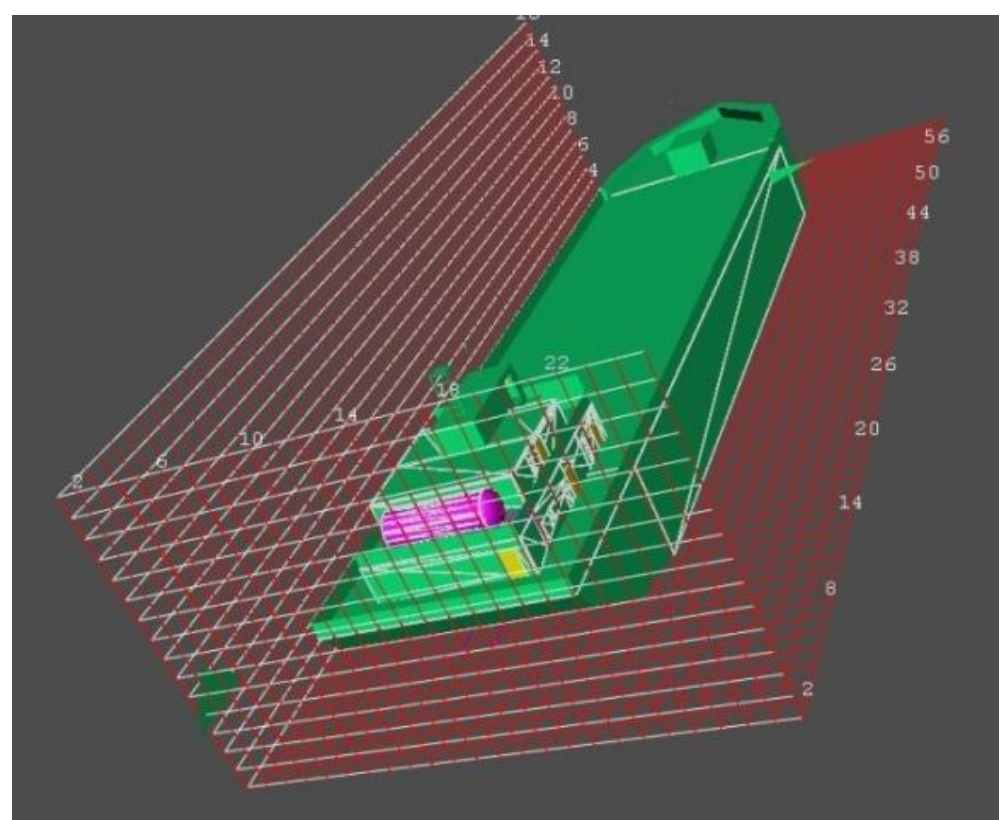

Fig. 4. 3D Model of Hongri 166.
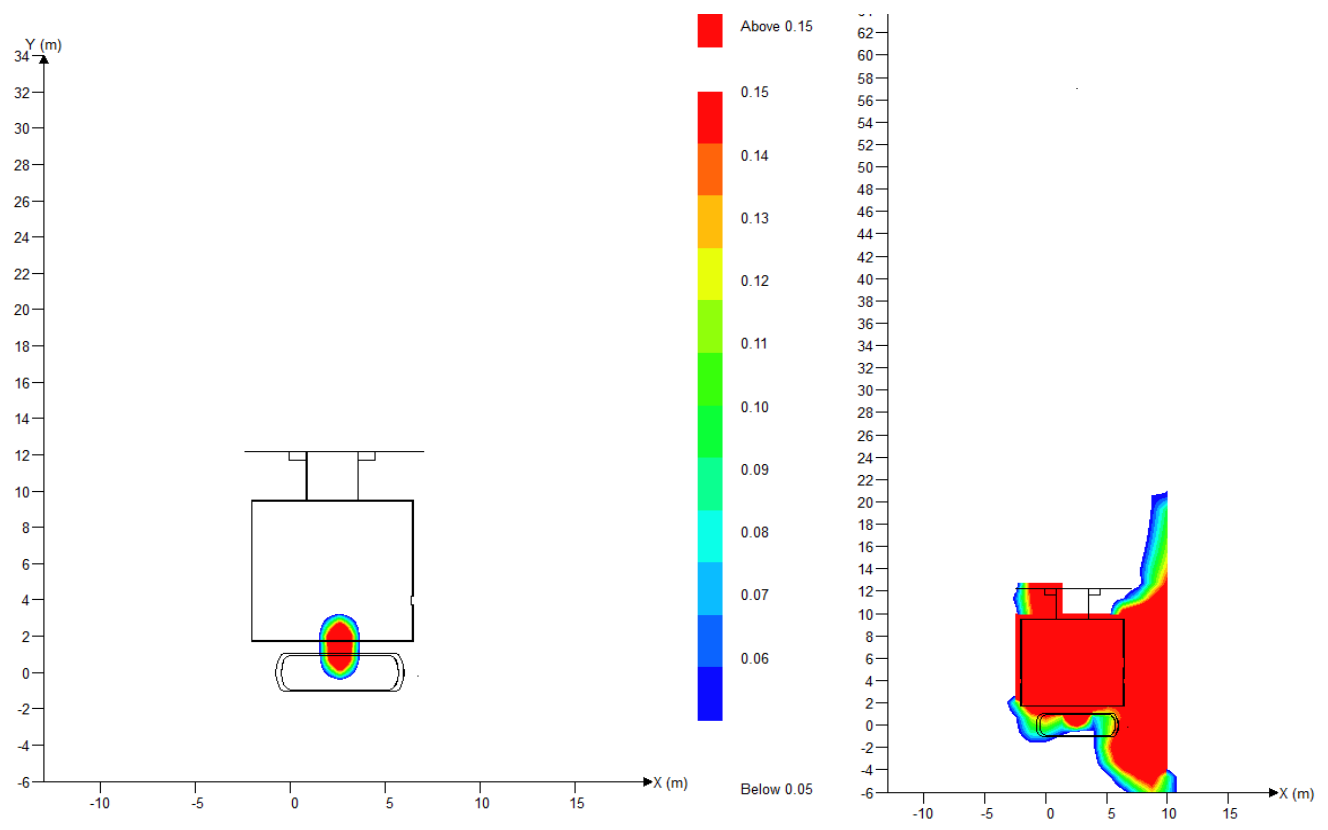


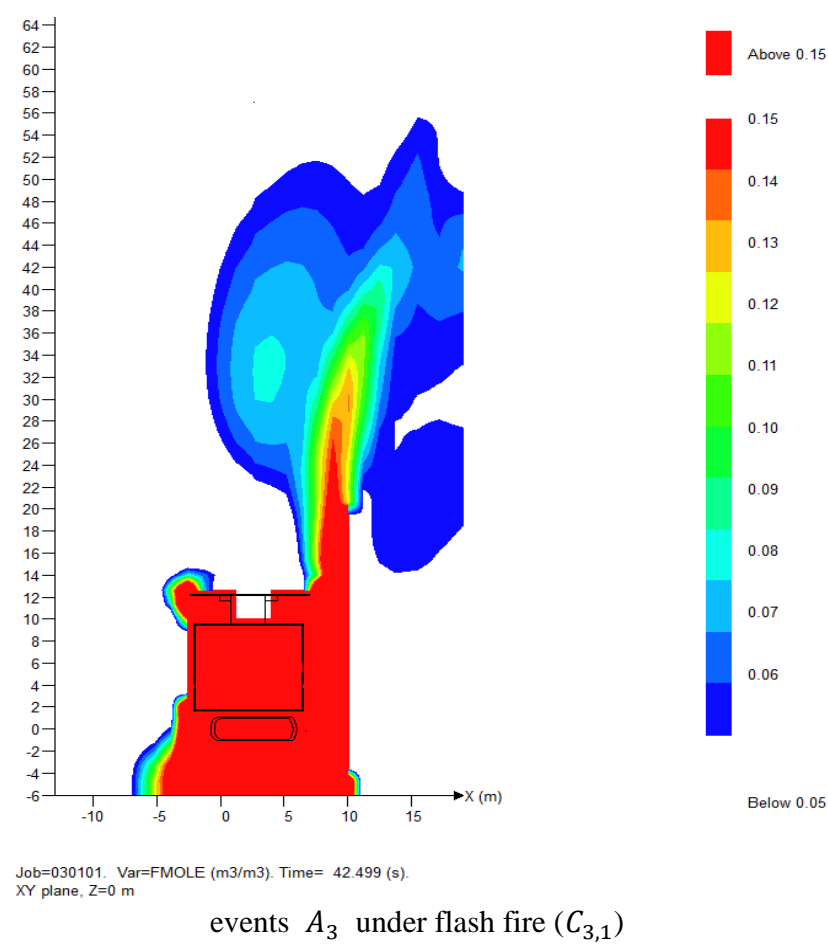

Fig. 5. CFD simulation results for the flash fire scenarios of event $A_{1}\left(C_{1,1}\right)$, event $A_{2}\left(C_{2,1}\right)$ and event $A_{3}\left(C_{3,1}\right)$.

According to the layout of the LNG-fueled cargo vessel in Fig. 2., it appears that most of the individuals working in the engine room and bridge near the LNG tank are less than 20.0 meters away from pipes, flange connections or valves. Considering the maximum radius of the dangerous zones of the coverage, this might lead to several fatalities for coverage extending more than 20.0 meters under flash fire. According to the classification of consequence severity given in Table 1, the consequences for the flash fire scenarios are given in Table 7.

Table 7

Consequences for the flash fire scenarios.

\begin{tabular}{ccc}
\hline Consequence $C_{i, 1}$ & Maximum Radius of dangerous zone (m) & Severity of consequence* \\
\hline$C_{1,1}$ & 3.24 & Serious (2) \\
$C_{2,1}$ & 20.5 & Catastrophic (4) \\
$C_{3,1}$ & 56.2 & Disastrous (5) \\
$C_{4,1}$ & 3.55 & Serious (2) \\
$C_{5,1}$ & 12.4 & Major (3) \\
$C_{6,1}$ & 2.98 & Serious (2) \\
$C_{7,1}$ & 3.62 & Serious (2) \\
$C_{8,1}$ & 3.42 & Serious (2) \\
$C_{9,1}$ & 12.4 & Major (3) \\
$C_{10,1}$ & 3.23 & Serious (2) \\
$C_{11,1}$ & 3.56 & Serious (2) \\
\hline
\end{tabular}

*The adopted evaluation criteria for consequence classification in accordance with the standards in (DNV and GL, 2012).

\subsubsection{Vapor cloud explosion}

For VCE accidents, the hazardous ranges of explosion are divided into 3 classes by overpressure: the minor injury grade is between $3.00 \mathrm{E}-02 \mathrm{Mpa}$ and $5.00 \mathrm{E}-02 \mathrm{Mpa}$, the serious injury grade is from $5.00 \mathrm{E}-02 \mathrm{Mpa}$ to $1.00 \mathrm{E}-$ $01 \mathrm{Mpa}$ and the death grade is above 1.00E-01 Mpa. The simulation results for the hazardous radius of the three classes are shown in Fig. 6. Therein, the blue fields refer to the damage distances of minor injury, serious injury and death grades, the maximum distance in the blue fields can be seen as the radius of each VCE scenario, and the second deck of the LNG-fueled ship - Hongri 166 is the referred part in each figure. 


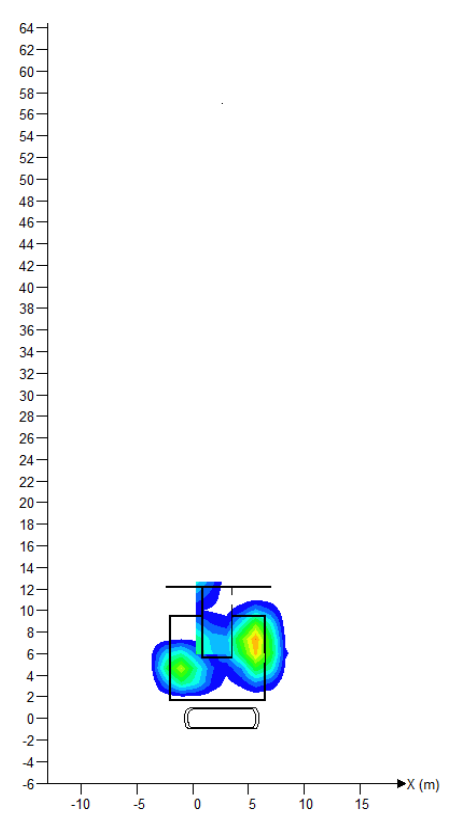

Job $=030101$. Var $=P R O D(-)$. Time $=40.853(\mathrm{~s})$
XY plane, $\mathrm{Z}=0 \mathrm{~m}$

minor injury grade of events $A_{2}$ under $\operatorname{VCE}\left(C_{2,2}\right)$

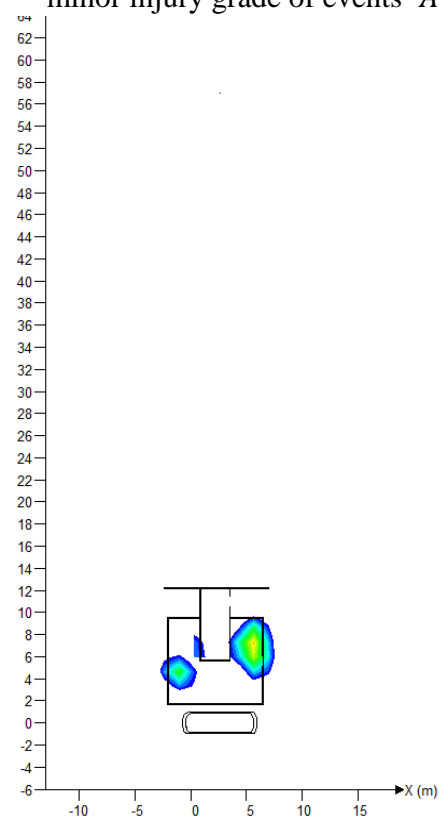

Job $=030101 . \mathrm{Var}=\mathrm{PROD}(\mathrm{-})$. Time $=40.853(\mathrm{~s})$.

death grade of event $A_{2}$ under $\operatorname{VCE}\left(C_{2,2}\right)$

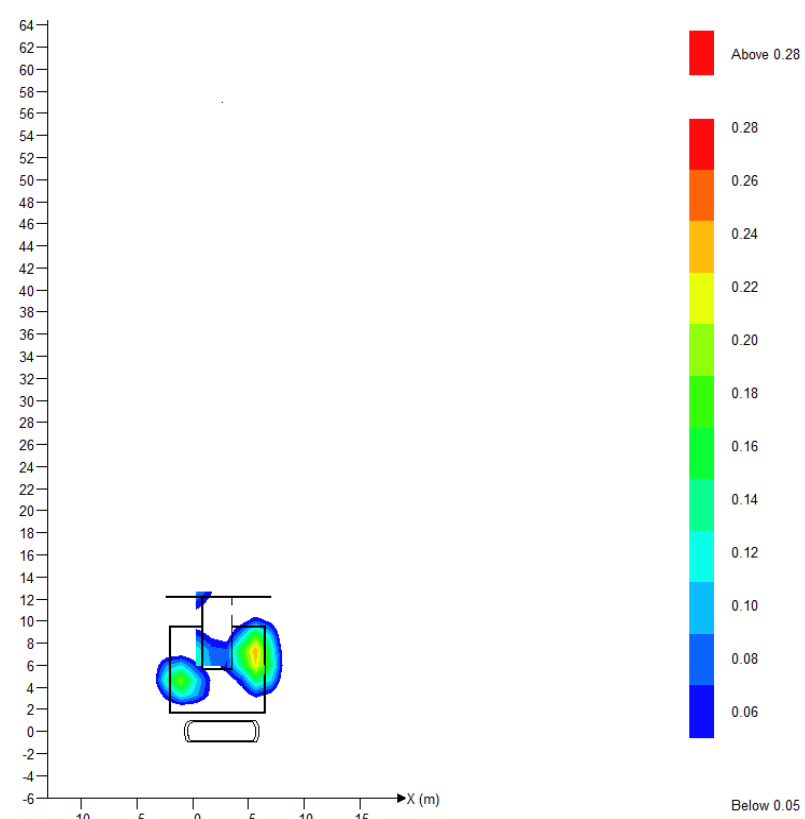

Job $=030101 . \mathrm{Var}=P R O D(-)$. Time $=40.853(\mathrm{~s})$
XY plane, $Z=0 \mathrm{~m}$

serious injury grade of events $A_{2}$ under $\operatorname{VCE}\left(C_{2,2}\right)$

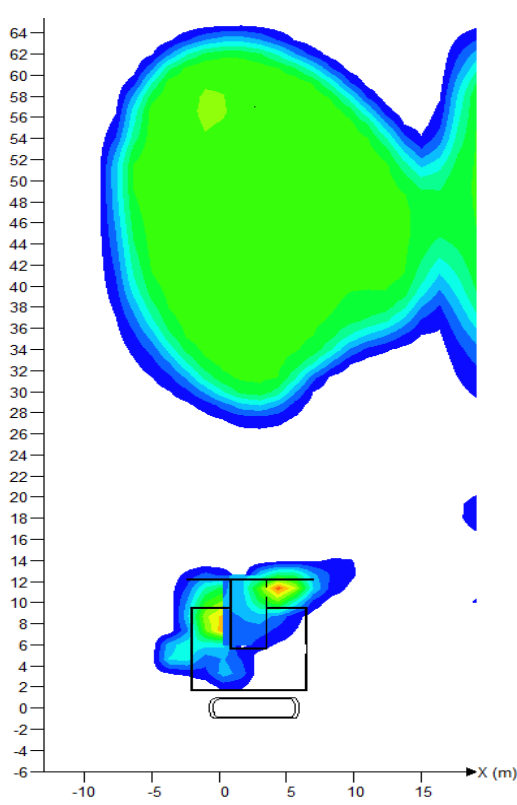

Above
0.29

0.28

0.27

0.26

0.25

0.24

0.23

0.22

0.21

0.20

0.19

0.18

0.17

0.16

0.15

0.14

0.13

0.12

elow 0.10

$\mathrm{J}$ ob $=030101 . \mathrm{Var}=\mathrm{PROD}(-), \mathrm{Time}=32.721(\mathrm{~s})$

minor injury grade of event $A_{3}$ under $\operatorname{VCE}\left(C_{3,2}\right)$ 


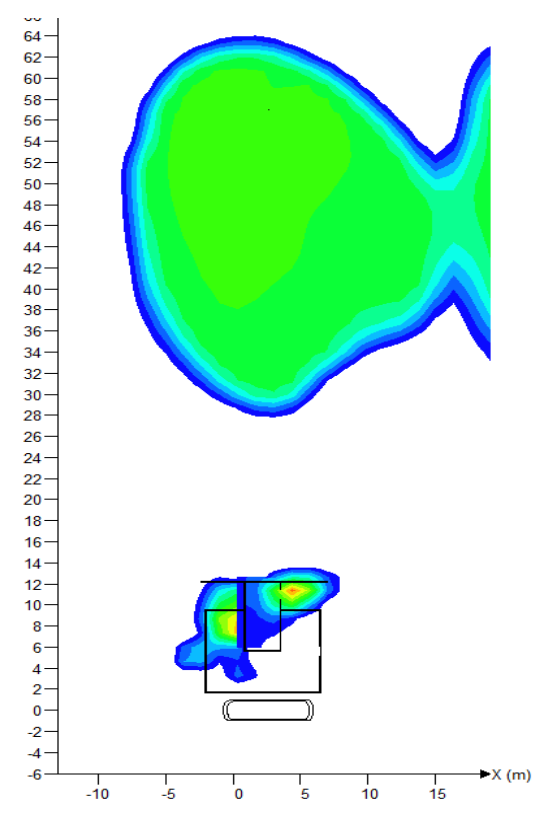

Job $=030101$. Var $=P R O D(-)$. Time $=32.721$ (s)
XY plane, $Z=0$ m

serious injury grade of event $A_{3}$ under $\operatorname{VCE}\left(C_{3,2}\right)$
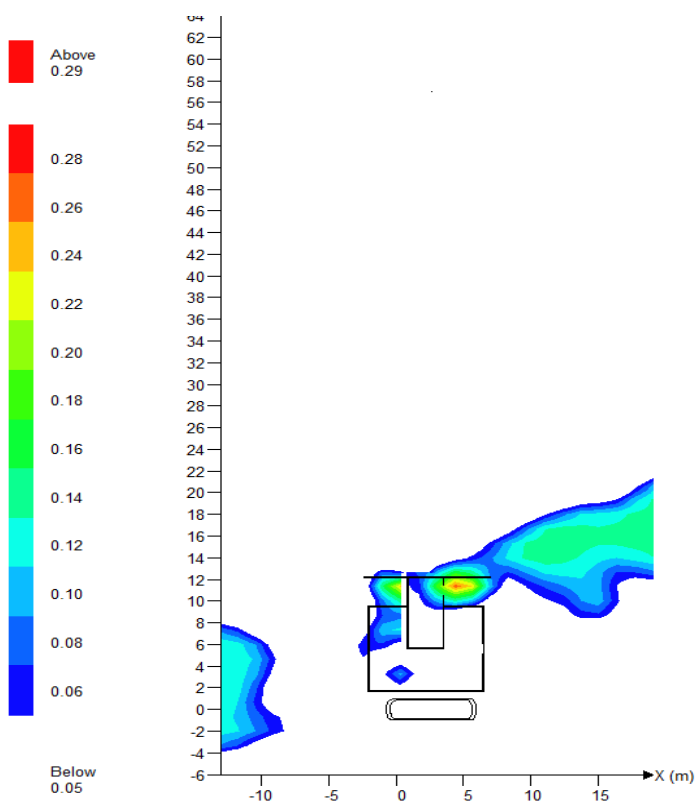

Job $=030101 . \mathrm{Var}=\mathrm{PROD}(-)$. Time $=31.864(\mathrm{~s})$
XY plane, $\mathrm{Z}=0 \mathrm{~m}$

death grade of event $A_{3}$ under $\operatorname{VCE}\left(C_{3,2}\right)$

Fig. 6. CFD simulation results for the VCE scenarios of event $A_{2}\left(C_{2,2}\right)$ and event $A_{3}\left(C_{3,2}\right)$.

The simulation results of event $A_{2}$ and event $A_{3}$ of VCE scenarios are presented in Table 8. For consequence $C_{2,2}$, the results of the simulation experiments give radiuses of $9.64 \mathrm{~m}, 9.33 \mathrm{~m}$ and $6.91 \mathrm{~m}$, delimiting the zones of minor injury, major injury and death, respectively. Corresponding, radiuses of $67.1 \mathrm{~m}, 51.6 \mathrm{~m}$ and $32.0 \mathrm{~m}$ represent the results for consequence $C_{3,2}$.

Table 8

Consequences for the VCE scenarios.

\begin{tabular}{ccccc}
\hline \multirow{2}{*}{ Consequence $C_{i, 2}$} & \multicolumn{3}{c}{ Radius (m) } & \multirow{2}{*}{ Severity of consequence } \\
\cline { 2 - 5 } & Minor injury grade & Serious injury grade & Death grade & \\
\hline$C_{2,2}$ & 9.64 & 9.33 & 6.91 & Catastrophic (4) \\
$C_{3,2}$ & 67.1 & 51.6 & 32.0 & Disastrous (5) \\
\hline
\end{tabular}

\subsection{Risk assessment}

The risk associated to generic event $A_{i}$ is calculated by adding the risks of flash fire and VCE scenarios. Using the severity of consequence of $\mathrm{S} 2$ as the base and event $\mathrm{A}_{2}$ as an example in terms of Eq. (1), the following can be obtained:

1. equivalent risk of flash fire accident for event $\mathrm{A}_{2}\left(R_{21}\right)=5.00 \mathrm{E}-06 * 0.336 * 100=1.68 \mathrm{E}-04$,

2. equivalent risk of VCE accident for event $\mathrm{A}_{2}\left(R_{22}\right)=5.00 \mathrm{E}-06 * 0.224 * 100=1.12 \mathrm{E}-04$,

3. total equivalent risk for event $\mathrm{A}_{2}\left(R_{2}\right)=R_{21}+R_{22}=2.80 \mathrm{E}-04$.

Since the severity of consequence of flash fire accident for event $A_{2}$ is S4, its equivalent risk is calculated by multiplying a transaction index $100\left(10^{4-2}\right)$ using the severity of consequence of S2 as the base.

The results for all the events are listed in Table 9 . The top three events count for nearly $20.0 \%$ of the total risk and should be allocated more efforts to formulate effective risk control options. The risk of medium and large leakages from the storage tank (events $A_{2}$ and $A_{3}$ ) take the first rank with $2.80 \mathrm{E}-04$ total risk, driven by large consequences of severity 4 and severity 5 , respectively: these events turn out to be found the most hazardous events for Hongri 166 LNG-fueled vessels. Small leakage of pipe DN10 (event $A_{6}$ ) is in third rank with 4.80 E-06 total risk, driven by the largest likelihood of occurrence of the initialing event, 1.00E-05. 
Table 9

Risk of event $A_{i}$ using the severity of consequence of $\mathrm{S} 2$ as the base.

\begin{tabular}{cccccc}
\hline & Event $A_{i}$ & Flash fire & Explosion & Total Risk & Ranking of the total risk \\
\hline$A_{1}$ & Storage tank $15 \mathrm{~m}^{3}$ (Small leakage) & $3.36 \mathrm{E}-08$ & N/A & $3.36 \mathrm{E}-08$ & 11 \\
$A_{2}$ & Storage tank $15 \mathrm{~m}^{3}$ (Medium leakage) & $1.68 \mathrm{E}-04$ & $1.12 \mathrm{E}-04$ & $2.80 \mathrm{E}-04$ & 1 \\
$A_{3}$ & Storage tank $15 \mathrm{~m}^{3}$ (Large leakage) & $1.68 \mathrm{E}-04$ & $1.12 \mathrm{E}-04$ & $2.80 \mathrm{E}-04$ & 1 \\
$A_{4}$ & Pipe DN40 (Small leakage) & $1.44 \mathrm{E}-06$ & N/A & $1.44 \mathrm{E}-06$ & 6 \\
$A_{5}$ & Pipe DN40 (Medium leakage) & $2.88 \mathrm{E}-06$ & N/A & $2.88 \mathrm{E}-06$ & 4 \\
$A_{6}$ & Pipe DN10 (Small leakage) & $4.80 \mathrm{E}-06$ & N/A & $4.80 \mathrm{E}-06$ & 3 \\
$A_{7}$ & Pipe DN10 (Large leakage) & $1.44 \mathrm{E}-07$ & N/A & $1.44 \mathrm{E}-07$ & 9 \\
$A_{8}$ & Flange connection or valve DN40 (Small leakage) & $1.33 \mathrm{E}-06$ & N/A & $1.33 \mathrm{E}-06$ & 7 \\
$A_{9}$ & Flange connection or valve DN40 (Medium leakage) & $1.66 \mathrm{E}-06$ & N/A & $1.66 \mathrm{E}-06$ & 5 \\
$A_{10}$ & Flange connection or valve DN10 (Small leakage) & $1.33 \mathrm{E}-06$ & N/A & $1.33 \mathrm{E}-06$ & 7 \\
$A_{11}$ & Flange connection or valve DN10 (Large leakage) & $7.20 \mathrm{E}-08$ & N/A & $7.20 \mathrm{E}-08$ & 10 \\
\hline
\end{tabular}

\section{Validation and recommendations}

\subsection{Validation}

The validation of the results has been made by comparison with the hazard identification (HAZID) report for generic LNG-fueled vessels proposed by DNV and GL (2012): the relevant part of its results are reported in Table 10. The same consequences criteria are applied for the description of the consequences in both studies. Even though different approaches are adopted in the risk assessment process, the results are in accordance. For the rankings, LNG leakage from the storage tank is the most hazardous event in both studies for any causes and most serious consequences, compared with pipes, flange connections and valves leakage.

Some differences are observed for other scenarios, like small leakages from flange connections. The major reason is the differences in operational conditions (like the different shipping lines) and management standards between China and Europe. For instance, the research scope of the European report concentrated on generic LNGfueled vessels, regardless of the difference among the storage tanks designs (i.e. A, B and C tanks) and the location of the storage tanks (i.e. underneath accommodation, inside accommodation with opening on top, underneath cargo area, on deck); on the contrary, this study focuses on a specific LNG-fueled cargo vessel with $\mathrm{C}$ tanks installed on the deck.

Table 10

Hazardous scenarios and Risk from (DNV and GL, 2012).

\begin{tabular}{|c|c|c|c|c|c|c|}
\hline & Event $A_{i}$ & Hazardous scenarios & Likelihood & $\begin{array}{l}\text { Severity of } \\
\text { consequence }\end{array}$ & Risk & Ranking \\
\hline$A_{1}$ & Storage tank $15 \mathrm{~m}^{3}$ (Small leakage) & $\begin{array}{l}\text { Breach/malfunction of tank } \\
\text { structure }\end{array}$ & Remote (1) & Disaster (5) & 6 & 3 \\
\hline$A_{2}$ & $\begin{array}{c}\text { Storage tank } 15 \mathrm{~m}^{3} \text { (Medium } \\
\text { leakage) }\end{array}$ & $\begin{array}{c}\text { Dropped objects or high } \\
\text { energy collision penetrating } \\
\text { LNG tank }\end{array}$ & $\begin{array}{l}\text { Very unlikely } \\
\text { (3) }\end{array}$ & $\begin{array}{l}\text { Catastrophic (4) } \\
\text { or Disaster (5) }\end{array}$ & $7 / 8$ & 2 \\
\hline$A_{3}$ & Storage tank $15 \mathrm{~m}^{3}$ (Large leakage) & $\begin{array}{l}\text { Hazards with portable LNG } \\
\text { fuel containers }\end{array}$ & $\begin{array}{l}\text { Very likely } \\
\text { (3) }\end{array}$ & Disaster (5) & 8 & 1 \\
\hline$A_{4}$ & Pipe DN40 (Small leakage) & Leak of pipe & $\begin{array}{c}\text { Extreme } \\
\text { unlikely (2) }\end{array}$ & Serious (2) & 4 & 8 \\
\hline$A_{5}$ & Pipe DN40 (Medium leakage) & Leak of pipe & $\begin{array}{l}\text { Extreme } \\
\text { unlikely (2) }\end{array}$ & Serious (2) & 4 & 8 \\
\hline$A_{6}$ & Pipe DN10 (Small leakage) & Leak of pipe & $\begin{array}{c}\text { Extreme } \\
\text { unlikely (2) }\end{array}$ & Serious (2) & 4 & 8 \\
\hline$A_{7}$ & Pipe DN10 (Large leakage) & Rupture of pipe & Remote (1) & Serious (2) & 3 & 11 \\
\hline$A_{8}$ & $\begin{array}{l}\text { Flange connection or valve DN40 } \\
\text { (Small leakage) }\end{array}$ & $\begin{array}{l}\text { Small leakage in flange } \\
\text { connection }\end{array}$ & Likely (5) & Moderate (1) & 6 & 3 \\
\hline$A_{9}$ & $\begin{array}{l}\text { Flange connection or valve DN40 } \\
\text { (Medium leakage) }\end{array}$ & $\begin{array}{l}\text { Large leakage in flange } \\
\text { connection }\end{array}$ & $\begin{array}{l}\text { Very unlikely } \\
\text { (3) }\end{array}$ & Major (3) & 6 & 3 \\
\hline$A_{10}$ & $\begin{array}{l}\text { Flange connection or valve DN10 } \\
\text { (Small leakage) }\end{array}$ & $\begin{array}{l}\text { Small leakage in flange } \\
\text { connection }\end{array}$ & Likely (5) & Moderate (1) & 6 & 3 \\
\hline$A_{11}$ & $\begin{array}{c}\text { Flange connection or valve DN10 } \\
\text { (Large leakage) }\end{array}$ & $\begin{array}{l}\text { Large leakage in flange } \\
\text { connection }\end{array}$ & $\begin{array}{c}\text { Extreme } \\
\text { unlikely (2) }\end{array}$ & Catastrophic (4) & 6 & 3 \\
\hline
\end{tabular}

\subsection{Recommendations}

Reduction of accident occurrence probability and consequences severity are the risk control objectives to achieve, guided by the risk assessment results. 
In order to decrease the LNG leakage probability, double-layered tubes, tank protection equipment and some other additional protection devices should be equipped to reduce the rupture probability of tanks, pipes, flange connections and valves, and then eventually prevent LNG diffusion into the atmosphere. For instance, tank protection equipment can be installed to decrease the hazard from dropped objects (cause 3), high energy collision (cause 6) and loss of protection (cause 8).

In order to limit the consequences, one way is to reduce the conditional probability of delayed ignition, as the event tree model lays out in section 3.3. To be specific, setting ventilation as blowing fan and some strategic methods such as installation of flange connections or valves in a higher location could be applied.

\section{Conclusions}

This paper proposes a framework for quantitatively assessing leakage risk of LNG-fueled vessels. The originality of the framework stands in the proposal of integrating ETA and CFD simulation. A systematic procedure is proposed to analyze and evaluate the likelihood of occurrence of the initiating events, the scenarios and the consequences. ETA and CFD methods are used to calculate the probability and consequence of LNG-fueled vessels leakage events in various scenarios. A real ship Hongri 166 is chosen as case study of reference to demonstrate the application of the proposed methodology. According to the simulation results in the case study, it is found that the medium and large leakages from the storage tank (event $A_{2}$ and event $A_{3}$ ) and small leakage of pipe DN10 (event $A_{6}$ ) could result in large risk. These results have been qualitatively compared with EU research outcomes and found to be in good agreement. Because of these results, some recommendations are proposed to improve the safety performance and safety management of LNG fueled vessels.

\section{Acknowledgements}

This study was supported by the EU FP7 Marie Curie IRSES project "REFERENCE" (No. 314836), advanced foreign experts project of SAFEA (China), and the Innovation Groups Project of Hubei Province Natural Science Foundation (No: 2013CFA007). The authors would also like to thank Mr. Bing Wang and Ms. Xiaozhen Lin for their help in the modeling of LNG-fueled ships.

\section{References}

Ale, B. J. M. (2002). Risk assessment practices in The Netherlands. Safety Science, 40(1), 105-126.

American Bureau of shipping. (2011). Guide for Propulsion and auxiliary systems for gas fueled ships.

Annex, V. I. of MARPOL 73/78. (1998). Regulations for the prevention of air pollution from ships and NOx technical code. IMO London. API, A. (2000). Publication 581: Risk-based inspection base resource document. American Petroleum Institute.

Arnold, DN; Brezzi, F; Cockburn, B; Marini, LD, 2002, "Unified analysis of discontinuous Galerkin methods for elliptic problems", Siam journal of numerical analysis, 29(5), pp. 1749-1779.

Aven, T. (2012). The risk concept—-historical and recent development trends. Reliability Engineering \& System Safety, 99, 33-44.

Bagniewski, M. (2010). LNG fuel for ships. A chance or a must? DNV (Det Norske Veritas), 4.

BEVI Reference Manual version 3.2, (2009) Bilthoven: RVIM.

Brett, B. C. (2008). Potential market for LNG-fueled marine vessels in the United States (Doctoral dissertation, Massachusetts Institute of Technology).

Chang, D., Rhee, T., Nam, K., Chang, K., Lee, D., \& Jeong, S. (2008). A study on availability and safety of new propulsion systems for LNG carriers. Reliability Engineering \& System Safety, 93(12), 1877-1885.

Changjiang River Administration of Navigational Affairs (2012). Changjiang River Shipping Development of 2012, China Communications Press, Wuhan.

China Academy of Safety Science and Technology (CASST). (2012). A Quantitative Risk Assessment Report of Diesel- LNG-fueled Fishing Boat.

Cormier, B. R., Qi, R., Yun, G., Zhang, Y., \& Mannan, M. S. (2009). Application of computational fluid dynamics for LNG vapor dispersion modeling: a study of key parameters. Journal of Loss Prevention in the Process Industries, 22(3), 332-352.

Council of the Society of risk analysis (SRA) (2015). Foundations of risk analysis, SRA Glossary.

CPR 18E. (1999). 'Purple book', Guideline for quantitative risk assessment. Part one: Establishments The Hague: RVIM.

Davies, P. A., \& Fort, E. (2013). LNG as a marine fuel: Likelihood of LNG releases. Journal of Marine Engineering \& Technology, 12(3), 3-10.

Veritas, D. N., \& Lloyd, G. (2012). Safety assessment of generic LNG fuelled vessel (No. 2012-0175, p. 13). Report.

El-Gohary, M. M. (2012). The future of natural gas as a fuel in marine gas turbine for LNG carriers. Proceedings of the Institution of Mechanical Engineers, Part M: Journal of Engineering for the Maritime Environment, 226(4), 371-377.

Elsayed, T. (2009). Fuzzy inference system for the risk assessment of liquefied natural gas carriers during loading/offloading at terminals. Applied Ocean Research, 31(3), 179-185.

EN 1473. (2006). Installation and equipment for liquefied natural gas - Design of onshore installations prEN 1473. rue de Stassart, 36 B-1050 Brussels: European National Standard, European Committee on Standardizations, Management Centre.

Fay, J. A. (2007). Spread of large LNG pools on the sea. Journal of hazardous materials, 140(3), 541-551. 
Fu, S., Yan, X., Zhang, D., Shi, J., Wan, C., \& Song, Z. (2014, June). Use of FMECA Method for Leakage Analysis of LNG-fueled Vessels. In ASME 2014 33rd International Conference on Ocean, Offshore and Arctic Engineering (pp. V04AT02A050V04AT02A050). American Society of Mechanical Engineers.

Gavelli, F., Davis, S. G., \& Hansen, O. R. (2011). Evaluating the potential for overpressures from the ignition of an LNG vapor cloud during offloading. Journal of Loss Prevention in the process industries, 24(6), 908-915.

Haimes, Y. Y. (2009). On the Complex Definition of Risk: A Systems-Based Approach. Risk analysis, 29(12), 1647-1654.

Hanna, S. R., Hansen, O. R., \& Dharmavaram, S. (2004). FLACS CFD air quality model performance evaluation with Kit Fox, MUST, Prairie Grass, and EMU observations. Atmospheric Environment, 38(28), 4675-4687.

Hansen, O. R., Gavelli, F., Ichard, M., \& Davis, S. G. (2010). Validation of FLACS against experimental data sets from the model evaluation database for LNG vapor dispersion. Journal of Loss Prevention in the Process Industries, 23(6), 857-877.

Hansen, O. R., \& Johnson, D. M. (2014). Improved far-field blast predictions from fast deflagrations, DDTs and detonations of vapour clouds using FLACS CFD. Journal of Loss Prevention in the Process Industries.

Harlow, F. H. (2004). Fluid dynamics in group t-3 los alamos national laboratory: (la-ur-03-3852). Journal of Computational Physics, 195(2), 414-433.

Hua, J., Wu, M., \& Kumar, K. (2005). Numerical simulation of the combustion of hydrogen-air mixture in micro-scaled chambers Part II: CFD analysis for a micro-combustor. Chemical engineering science, 60(13), 3507-3515.

International Maritime Organization (IMO). (2009). Interim guidelines on safety for natural gas fueled engine installations in ships, 2.1 .1 risk analysis. MSC. 285(86).

International Maritime Organization (IMO). (2014). International code of safety for ships using gases or other low-flashpoint fuels (IGF code).

Fay, J. A. (2003). Model of spills and fires from LNG and oil tankers. Journal of Hazardous Materials, 96(2), 171-188.

Kumar, S., Kwon, H. T., Choi, K. H., Lim, W., Cho, J. H., Tak, K., \& Moon, I. (2011). LNG: An eco-friendly cryogenic fuel for sustainable development. Applied Energy, 88(12), 4264-4273.

Lee, S., Seo, S., \& Chang, D. (2015). Fire risk comparison of fuel gas supply systems for LNG fuelled ships. Journal of Natural Gas Science and Engineering, 27, 1788-1795.

Lowrance W. (1976). Of Acceptable Risk-Science and the Determination of Safety. Los Altos, CA: William Kaufmann Inc.

National Fire Protection Association. (2009). NFPA 59A: Standard for the production, storage, and handling of liquefied natural gas (LNG) (Edition). Quincy, MA: National Fire Protection Association. Quincy, MA.

Norwegian Technology Centre. (2001). Risk and emergency preparedness analysis (NORSOK STANDARD, z-013).

Nwaoha, T. C., Yang, Z., Wang, J., \& Bonsall, S. (2013). A fuzzy genetic algorithm approach for analysing maintenance cost of high risk liquefied natural gas carrier systems under uncertainty. Journal of Marine Engineering \& Technology, 12(2), 57-73.

Paltrinieri, N., Tugnoli, A., \& Cozzani, V. (2015). Hazard identification for innovative LNG regasification technologies. Reliability Engineering \& System Safety, 137, 18-28.

Pitblado, R. M., \& Woodward, J. L. (2011). Highlights of LNG risk technology. Journal of Loss Prevention in the Process Industries, 24(6), 827-836.

Raj, P. K., \& Lemoff, T. (2009). Risk analysis based LNG facility siting standard in NFPA 59A. Journal of Loss Prevention in the Process Industries, 22(6), 820-829.

Reason, J. T. (1997). Managing the risks of organizational accidents (Vol. 6). Aldershot: Ashgate.

Ren, J., Jenkinson, I., Sii, H. S., Wang, J., Xu, L., \& Yang, J. B. (2005). An offshore safety assessment framework using fuzzy reasoning and evidential synthesis approaches. Journal of Marine Engineering \& Technology, 4(1), 3-16.

Ronza, A., Vilchez, J. A., \& Casal, J. (2007). Using transportation accident databases to investigate ignition and explosion probabilities of flammable spills. Journal of hazardous materials, 146(1), 106-123.

SINTEF Industrial Management. (2002). OREDA: Offshore reliability data, SINTEF industrial management. Trondheim, Norway: SINTEF Industrial Management.

Vanem, E., Antão, P., Østvik, I., \& de Comas, F. D. C. (2008). Analysing the risk of LNG carrier operations. Reliability Engineering \& System Safety, 93(9), 1328-1344.

Vílchez, J. A., Espejo, V., \& Casal, J. (2011). Generic event trees and probabilities for the release of different types of hazardous materials. Journal of Loss Prevention in the Process Industries, 24(3), 281-287.

Woodward, J. L., \& Pitbaldo, R. (2010). LNG Risk Based Safety: modeling and consequence analysis. John Wiley \& Sons.

Yun, G., Rogers, W. J., \& Mannan, M. S. (2009). Risk assessment of LNG importation terminals using the Bayesian-LOPA methodology. Journal of Loss Prevention in the Process Industries, 22(1), 91-96.

Zio, E. (2007). An introduction to the basics of reliability and risk analysis (Vol. 13). World scientific.

Zio, E., Baraldi, P., Librizzi, M., Podofillini, L., \& Dang, V. N. (2009). A fuzzy set-based approach for modeling dependence among human errors. Fuzzy Sets and Systems, 160(13), 1947-1964. 